\title{
Feasibility of liposuction for treatment of arm lymphedema from breast cancer: A prospective study and review of the literature
}

\author{
Erin Louise Doren ${ }^{1 *}$, Paul David Smith ${ }^{1,2}$, Weihong Sun ${ }^{2}$, Mensura Lacevic ${ }^{2}$, William Fulp ${ }^{3}$, Rebecca Reid ${ }^{4}$ and Christine Laronga $^{2}$ \\ ${ }^{1}$ Division of Plastic Surgery, Department of Surgery, University of South Florida, USA \\ ${ }^{2}$ Department of Women's Oncology, Comprehensive Breast Program, H. Lee Moffitt Cancer Center, USA \\ ${ }^{3}$ Biostatistics, Comprehensive Breast Program, H. Lee Moffitt Cancer Center, USA \\ ${ }^{4}$ Physical Therapy, Comprehensive Breast Program, H. Lee Moffitt Cancer Center, USA
}

\begin{abstract}
Lymphedema is a dreaded complication of breast cancer treatment affecting $20 \%$ of women having axillary node dissection. We explored the feasibility of liposuction to reduce volume and thus arm lymphedema. A prospective trial of women with unilateral arm lymphedema from breast cancer treatment was conducted. Arm measurements, volumes (water displacement and geometric calculation), muscle strength differences and quality of life/functionality were measured pre-operatively and post-operatively at 6 weeks, 6 months and yearly up to 5 years.

Six patients had liposuction. Average age was 52.8 yrs. Average percent volume reductions at 6 weeks, 6 months and 1 year were $70 \%$, $47 \%$, $71 \%$ mls geometrically and $63 \%, 18 \%, 54 \%$ by water displacement. 1 patient had cellulitis at 4 months and had no other adverse events. Quality of life and functionality were not statistically significant. Pain decreased. Mean grip strength improved.

Liposuction can safely reduce volume of arm lymphedema and may improve functionality/quality of life. Larger studies with longer follow-up are required to validate the durability of these early results.
\end{abstract}

\section{Introduction}

Lymphedema is a dreaded complication of breast cancer treatment that affects approximately $20 \%$ of women having axillary lymph node dissection [1]. It is defined as an abnormal regional accumulation of protein-rich interstitial fluid, resulting in edema formation and eventual chronic inflammation with or without fibrosis [2]. Risk factors for the development of lymphedema after axillary lymph node dissection are advanced age, radiation, obesity, metastasis to lymph nodes and postsurgical complications like seroma [2]. Handley in 1908 was the first to describe the "brawn arm" associated with untreated advanced breast cancer [3]. In 1921 Halsted reported on "Elephantiasis Chirurgica, its cause and prevention" occurring after radical mastectomy [4]. Patients with lymphedema often have difficulty with activities of daily living caused by: limitations in range of motion, pain, numbness and weakness in the affected extremity [5]. Psychological morbidity including a decline in emotional and social well-being has also been documented in patients suffering from lymphedema $[6,7]$.

The goal of lymphedema treatment is to decrease swelling, restore function and improve discomfort in and cosmesis of the affected limb. Conservative and surgical methods have been used with often less than optimal success. Current conservative treatment modalities include; arm elevation, exercise, lymphatic drainage techniques and controlled compression. Manual lymphatic drainage was introduced by Vodder in 1936; this technique uses massage to improve lymph flow [8]. Complete decongestive physiotherapy was developed by Foeldi in 1985 and consists of manual lymphatic drainage, compressive bandaging and exercise [9]. Pneumatic compression devices are another popular technique to improve lymphatic drainage, using an air compressor unit that attaches to a garment sequentially inflating and deflating creating a treatment effect [10].

Surgical therapy for lymphedema was first described by Charles, who in performed a wide excision of scrotal edema with skin grafting [11]. This excisional technique was applied by others to arm lymphedema, which is still used today but largely limited by its number of complications. O'Brien et al. reported on microlymphatic ovenous anastomoses for the treatment of obstructive lymphedema [12]. A decade later, in 1988, Nava published the first case of a patient treated with liposuction for an edematous arm [13]. The most noted advocate for liposuction as a treatment for lymphedema is Brorson, who started to use liposuction for arm lymphedema in 1987 [14]. Brorson reported his experience with liposuction extensively starting with a study of 28 women who after 12 months had an average reduction in arm volume

Correspondence to: Erin Louise Doren, MD, Division of Plastic Surgery, Department of Surgery, University of South Florida, 2 Tampa General Circle, 7th Floor mailroom, Tampa, FL 33606, USA, Tel: 813-259-8510; Fax: 813-8441947; E-mail: edoren@gmail.com

Key words: upper extremity lymphedema, liposuction, surgical treatment of lymphedema, axillary lymph node dissection, complications of breast cancer surgery

Received: May 15, 2015; Accepted: May 30, 2015; Published: June 04, 2015 
of $106 \%$ [15]. In 2003 Brorson updated his results: with 48 patients treated with liposuction, after 48 months $(\mathrm{n}=12)$, an average reduction in volume of edema of $100 \%$ was found, showing the longevity of results [14]. Liposuction has similarly been used with success for the treatment of lower-extremity lymphedema [16-18].

To date there are a select number of publications addressing the feasibility of liposuction for the treatment of chronic arm lymphedema, resulting from the treatment of breast cancer. Brorson's group as well as a few others document its successful use, however experience reported in the U.S. literature is scarce $[17,19,20]$. Our objective was to explore the feasibility of liposuction to reduce fat volume and thus arm lymphedema, restoring function and improving cosmesis of the limb in an American study population. We report our protocol and review our early results with this technique.

\section{Methods and materials}

\section{Pre-operative assessment and inclusion criteria}

An IRB-approved prospective trial was conducted of women having non-pitting chronic unilateral arm lymphedema resulting from breast cancer treatment. Informed consent was obtained from all patients. Patients included in this study had mild to severe lymphedema; classification was based on the difference in volume of the affected arm compared to the unaffected arm: slight $(<150 \mathrm{ml})$, mild $(150-400 \mathrm{ml})$, moderate $(400-800 \mathrm{ml})$, severe $(>800)$.

At the time of enrollment no patients had evidence of active cancer, arm cellulitis, open wounds or pitting edema. All patients had undergone multiple previous conservative therapies, but none had surgical treatment for lymphedema.

\section{Data collection}

Data was collected at each patient visit starting at the pre-operative visit, then post-operatively at 2 weeks, 6 weeks, 6 months, 1 year and yearly afterwards for a planned five years. Patient independent variables included; age, height and weight, type of breast cancer surgery, reconstruction, number of lymph nodes removed, number of nodes with cancer, radiation treatment, chemotherapy, hormone therapy, previous arm infections, previous therapy for lymphedema and garment use.

The functional assessment of cancer therapy breast scale (FACT-B +4 , version 4 ) was used to assess patient quality of life measures [21]. This questionnaire follows a Likert scale of $0-4$. We have arranged the data so that 0 represents the most negative value and 4 the most positive. The questionnaire has been previously validated and assesses physical well-being, social/family well-being, emotional well-being, functional well-being, and breast surgery related concerns.

Dependent variables recorded post-operatively included; arm measurements (circumferential), arm volume (water displacement and geometric methods), muscle strength differences between the affected and unaffected arms and quality of life/functionality. Water displacement was calculated by weighing displaced water to the nearest $5 \mathrm{~g}$, corresponding to $5 \mathrm{~mL}$. Both arms are always measured at each visit, and the difference in arm volumes is designated as the edema volume. The geometric calculation of volume was achieved using the Frustum method (Figure 1) [22]. Hand grip strength was quantified by measuring the amount of static force that the hand can squeeze around a dynamometer and measured in pounds. The patient's grip strength post-operatively of the involved verses the uninvolved arm was measured at each visit.

$$
\mathrm{V}_{\text {frustum }}=\frac{1}{12 \pi} \sum_{\mathrm{i}-1}^{\mathrm{n}} \mathrm{L}\left(\mathrm{C}_{\mathrm{i}}^{2}+\mathrm{C}_{\mathrm{i}} \mathrm{C}_{\mathrm{i}-1}+\mathrm{C}_{\mathrm{i}-1}{ }^{2}\right)
$$

Figure 1. Geometric formula used to calculate the volume of the arm.

C: Circumference of arm

$\mathrm{C}_{\mathrm{i}-1}$ : Circumference of arm at more proximal measurement

$\mathrm{L}$ : length of arm segment between $\mathrm{C}$ and $\mathrm{C}_{\mathrm{i}-1}$

\section{Liposuction technique}

The surgical procedure was performed by a single surgeon at our institution and a routine protocol was followed. All patients received a pre-operative antibiotic. A series of small incisions $\sim 3-4 \mathrm{~mm}$ in size were made in the affected arm, forearm, and/or hand. A Hunstead needle was used to inject a "wetting solution" containing 1 liter of Lactated Ringer's solution with $50 \mathrm{cc}$ of $1 \%$ xylocaine and 1 ampule of Epinephrine. 3 and $4 \mathrm{~mm}$ liposuction catheters were then used to circumferentially remove edematous fat as completely as possible. Ace compression wraps were placed from the fingertips to the shoulder in the operating room to provide hemostasis.

\section{Post-operative care}

On post-operative day 2, all patients had their operative bandage removed by the surgeon and the skin was inspected. Then a physical therapist re-wrapped the arm using a lymphedema bandage. Postoperatively patients were required to remove the dressing for bathing and skincare of the operative arm. After showering they were instructed to reapply the lymphedema compression wraps for 2 weeks. At 2 weeks, each patient was fitted for a compression sleeve that was worn during the day and removed at night in exchange for the multi-layered bandage, for a total of 6 weeks. Thereafter, the garment could be taken off only at night, as the patients were instructed pre-operatively that expected continued garment use would be life-long.

As aforementioned, skin inspection, edema volume measurements, arm functionality assessment and quality of life were re-assessed at 6 weeks, 6 months, one year and yearly thereafter until year 5. Due to anticipated changes in arm measurements during the first year postoperatively, new compression sleeves would be fitted at 6 months and one year.

\section{Statistical analysis}

Data is described as percentages, means or median with ranges as appropriate. A t-test was used to compare the difference in preoperative and post-operative arm volume by geometric and water displacement. T-test was also used to compare the quality of life scores pre-operatively and post-operatively.

\section{Results}

Six patients were enrolled and underwent the liposuction procedure from $12 / 2008-4 / 2011$. The average age was 52.8 years with a range of 43-60 years. The time patients were living with lymphedema prior to participation in this study was 1.6-6.5 years. Of the six patients, one patient did not return after the two-week post-operative visit for her arm measurements. The remaining patients have been followed from 1-5 years. The average volume difference between the affected and unaffected arms at baseline was $562.6 \mathrm{mls}$ (range 176-868 mls) by geometric calculation and $567 \mathrm{mls}$ (range $219-770 \mathrm{mls}$ ) by water 
displacement. Patients had mild to severe lymphedema, most falling into the moderate category $(400-800 \mathrm{ml})$. Three patients had total mastectomy with axillary lymph node dissection and three had partial mastectomy with axillary lymph node dissection. Descriptive statistics can be found in Table 1.

Median volume of fat aspirated from the arm by liposuction was $700 \mathrm{mls}$ (range $350-700 \mathrm{mls}$ ). No immediate surgical complications (within 30 days) occurred. One patient developed cellulitis requiring antibiotics at four months post-operatively which resulted in an increase in lymphedema volume. This accounted for a temporary increase in the median calculated arm edema for the entire study cohort at the six-month data point. By one year, the transient rise in lymphedema volume was no longer evident.

The average percent volume reductions for 5 of the 6 women at 6 weeks, 6 months, 1 yearpost-operatively were $70 \%, 47 \%$, 71\% mls geometrically and $63 \%, 18 \%, 54 \%$ by water displacement respectively (Figure 2a and 2b). Two patients have now been followed for 5 years with one having a $153 \% / 121 \%$ reduction at five years, by geometrically and water displacement respectively, while the other patient has had recurrence of edema with a $-165 \% /-110 \%$ change in volume. Although there is a trend toward decreasing arm volumes at 1 year, the population size was too small for statistical significance. A t-test

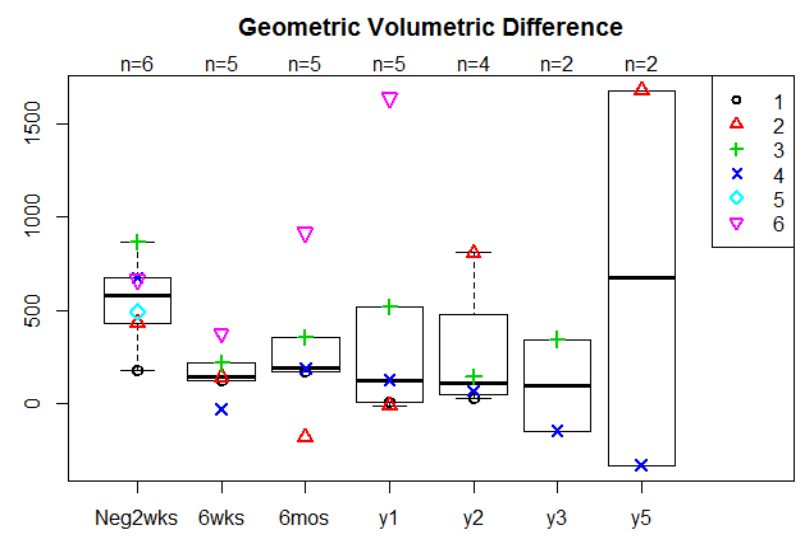

Figure 2a. Median arm volume reductions by geometric calculation in mls.

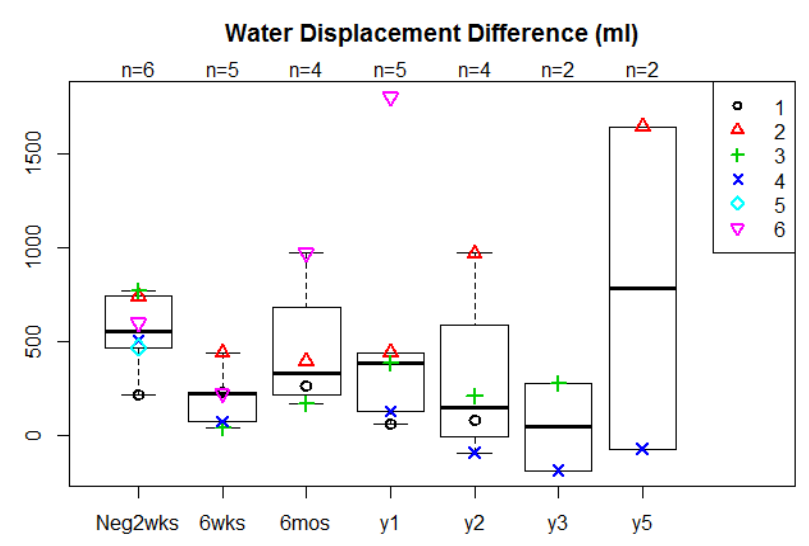

Figure 2b. Median arm volume reductions by water displacement in $\mathrm{ml}$.
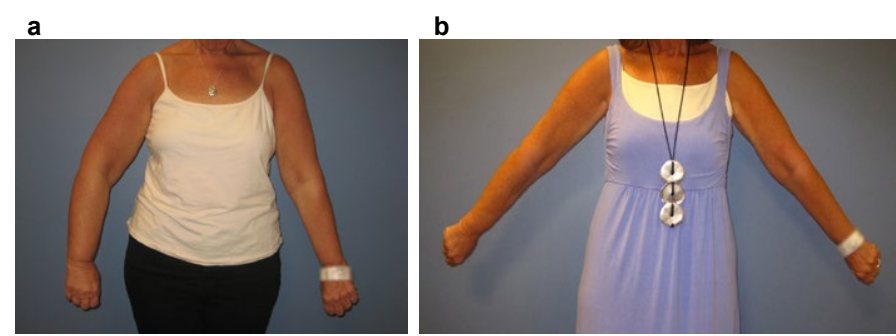

Figure 3. Pre-operative (a) and post-operative (b) photos demonstrating utility of liposuction for right arm lymphedema.

comparing the pre-operative difference in arm volume to the six month post-operative difference in arm volume by geometric and water displacement calculations respectively revealed the following $\mathrm{p}$-values, $\mathrm{p}=0.181$ and $\mathrm{p}=0.58$. When comparing the pre-operative to 1 year postoperative results using geometric and water displacement, $\mathrm{p}$-values were, $p=0.722$ and $p=0.993$ respectively.

Quality of life and functionality scores were calculated as total per patient, on a Likert scale $0-4,4$ being most positive. As sample size was small, no statistical significance was found in regards to quality of life change over time, $\mathrm{p}$-values range from $0.181-1.100 \%$ of patients reported no pain at the 1-year follow up. Grip strength improved dramatically for one patient with $4 / 6$ displaying minimal change at 1 year. The mean grip strength of the involved arm at baseline was 26.33lbs, at 6 weeks $25.83 \mathrm{lbs}, 6$ months $33.8 \mathrm{lbs}$, and 1 -year $32.5 \mathrm{lbs}$. A t-test comparing the pre-operative arm strength to the 6 month and 1 year post-operative strength revealed no statistical significance, $p=0.167$ and $p=0.202$ respectively. Pre-operative and post-operative photos in Figure 3 demonstrate the clinical utility of liposuction for reduction of arm lymphedema.

\section{Discussion}

Lymphedema is a complication of breast cancer treatment that is commonly treated with conservative, non-surgical measures. The pathophysiology of lymphedema is such that the removal of axillary lymph nodes interferes with normal lymph drainage from the arm. The accumulation of interstitial fluid increases tissue pressure and this in turn reduces micro-vascular blood flow. The inter-relationship between microvascular blood flow and subcutaneous fat is not completely understood, however slow flow rate is a condition that spurs lipogenesis and deposition of fat, then adipose hypertrophy occurs [23]. Brorson et al. showed in a study using dual energy $\mathrm{x}$-ray absorptiometry that the lymphedematous arm has a significant increase in soft tissue, $73 \%$ more fat, $47 \%$ more muscle and $7 \%$ more bone by volume then the unaffected arm [24]. Conservative measures and lymphovenous bypass may improve lymphatic flow in the early stages of pitting lymphedema when predominantly fluid remains in the tissues. Once non-pitting edema occurs, the overall accumulation of fat in the tissue can only effectively be removed by liposuction or excisional techniques [25].

The technique of liposuction was first developed in the 1970s and widely popularized in the early 1980 s by a French surgeon Illouz [26]. Since then liposuction has proven to be a safe and reliable method to treat lipodystrophy. Brorson et al. investigated the effect of liposuction on lymph transport to disprove the theory that liposuction may impair the already impaired lymph transport. Using indirect lymphoscintigraphy in 20 patients with arm lymphedema before and after liposuction, they found that the already decreased lymph transport was not further reduced after liposuction, it was essentially 
unchanged $[27,28]$. Based on these findings we consider liposuction a safe procedure for the treatment of lymphedema.

Although it did not reach statistical significance, our study demonstrates a noted decrease in volume of the affected arm at 6 weeks, 6 months and 1 year after treatment with liposuction. Reduction in volume was noted by geometric calculation as well as by volume displacement. These measurements have been shown to correlate strongly but are not mutually exclusive and therefore both are used to assess changes in arm volume [22]. The overall reduction in volume at the six month mark (18-47\%) is decreased compared to the other values as it has been skewed by a single patient who had cellulitis increasing arm edema at four months. As expected percent decrease in volume trends back up at the 1-year mark with only one patient followed up to five years showing significant improvement.

Brorson proposes that chronic non pitting arm lymphedema of up to $4 \mathrm{~L}$ in excess can be treated with liposuction [17]. His longterm results show significant decreases in arm volume, $104 \%$ at 1 year, $106 \%$ at 4 years, without recurrence [27]. Our reduction in arm volumes did not reach the $100 \%$ reductions, found in Brorson's studies. As our mean excess arm volumes were moderate (562.6 and $567 \mathrm{mls}$ by geometric and water displacement) and liposuction aspirate uniformly lower (700mls), this may have contributed to our decreased reduction in arm volumes. We may need to be more aggressive with our liposuction technique and thus achieve more volume reduction in the future. Other investigators performing liposuction found similarly positive results using Brorson's liposuction method. Schaverien et al. reported reduction in arm volume over a 5 year time period, with $101 \%$ reduction reported at 1 year in 12 patients [19]. Continued reduction in volume has been attributed to the continued use of compression garments. Damstra et al. show similar findings with a reduction in volume of $118 \%$ at 1 year in 37 patients [20].

How do these findings compare to conservative therapies? Exact measure of outcomes of conservative modalities varies from study to study. Most studies have shown reductions in volume or circumference of arm lymphedema, but no total corrections and often these results trail off at the 1 year mark [29]. In a randomized controlled trial, evaluating pneumatic compression for treatment of postmastectomy lymphedema, they found no significant improvement compared to the control group [30]. In a randomized study comparing manual lymphatic drainage to pneumatic compression devices, they found $15 \%$ reduction in arm volume in the manual lymphatic drainage group and a $7 \%$ reduction in the pneumatic compression group, with no significant difference between groups [31]. Brorson et al. evaluated liposuction with compression therapy verses compression therapy alone in 28 patients $[27,32]$. They found in the compression therapy alone group a $47 \%$ reduction of volume at 1 year, and in the liposuction group a $113 \%$ volume reduction at 1 year [27]. They additionally showed that removal of the compression garment at 1 year for 1 week, in patients treated with liposuction, increased the volume on average by $370 \mathrm{ml}$, reversed by re-compression [27,32]. Therefore life-long use of compression therapy is imperative.

Others have proposed a multi-modality approach using liposuction with myocutaneous flaps and lymph-fascia grafts for treatment of lymphedema and found significant decrease in arm circumference in a study of 11 patients [33]. Microsurgical techniques for lymphovenous bypass have varying results. In a prospective study by Damstra et al. 10 patients underwent lymphatic venous anastomosis, they found only a $2 \%$ reduction in arm volume at 1 year and minimal improvement in quality of life [34]. In1990 O'Brien reported a series of 52 patients treated with lymphatic-venous anastomoses [35]. They showed an average volume reduction of the treated extremity of $44 \%$ with some having 4-year follow up showing a reduction of $26 \%$ [35]. Other authors experience with lymphatic-venous anastomoses has shown modest improvements in arm volume of 30-50\% [36]. Lymphovenous bypass may have efficacy for early stage lymphedema but is less likely to affect late-stage disease, as tissues have extensive fibrosis [36].

Aside from arm volume reduction, benefits of liposuction procedure also include increased quality of life and functionality. We assessed quality of life by survey, but were unable to achieve statistical significance, as our sample size was small. Schaverien et al. found significant reduction in patient reported anxiety and depression scores [19]. Brorson et al. found that in the liposuction group compared to compression therapy alone, the sensation of swelling, heaviness, fatigue and pain decreased after treatment, but for more physiological related factors and social life, there were few effects of treatment [37]. In addition reduction of volume likely decreases the incidence of cellulitis as total blood flow in the lymphedematous arm has been shown to increase significantly after liposuction [27]. We had only 1 of 6 patients that reported a post-operative cellulitis.

\section{Conclusion}

Liposuction is one of many modalities available to treat arm lymphedema from the treatment of breast cancer. It has been shown to safely reduce arm volume and may improve functionality and quality of life. Those who should be considered for this procedure have chronic secondary non-pitting lymphedema, have failed conservative measures, and are willing to continue with compression therapy post-operatively. In order for this treatment to reach optimal success an interdisciplinary team should be in place. The use of compression garments continues to be life long as it helps decrease the rate of recurrence. Larger studies with longer follow up are required to validate our early results.

\section{Conflicts of interest}

The authors of this article do not have any conflicts of interest in the manuscript, including financial, consultative, institutional, or other relationships that might lead to bias. This study was conducted under the approval of the Institutional Review Board (IRB) at Moffitt Cancer Center where the study was conducted.

\section{Acknowledgements}

Support and funds for this research study were provided by the Park Foundation, Don Shula Foundation and the Florence and Leslie Edgar Charitable Trust Fund, from July 2008 until June of 2011, in the amount of $\$ 90,000$.

\section{References}

1. DiSipio T, Rye S, Newman B, Hayes S (2013) Incidence of unilateral arm lymphoedema after breast cancer: a systematic review and meta-analysis. Lancet Oncol 14: 500-515. [Crossref]

2. Sakorafas GH, Peros G, Cataliotti L, Vlastos G (2006) Lymphedema following axillary lymph node dissection for breast cancer. Surg Oncol 15: 153-165. [Crossref]

3. Handley WS (1908) Lancet: 783-785.

4. Halstead WS (1921) Swelling of the arm after operations for cancer of the breast elephantiasis chirurgica; its cause and prevention. Bull Johns Hopkins Hosp 32: 309.

5. Maunsell E, Brisson J, Deschênes L (1993) Arm problems and psychological distress after surgery for breast cancer. Can J Surg 36: 315-320. [Crossref]

6. Sneeuw KC, Aaroson NK, Yarnold JR, Broderick M, Regan J, et al. (1992) Cosmetic 
and functional outcomes of breast conserving treatment for early stage breast cancer. 2 . Relationship with psychosocial functioning. Radiother Oncol 25: 160-166. [Crossref]

7. Tobin MB, Lacey HJ, Meyer L, Mortimer PS (1993) The psychological morbidity of breast cancer-related arm swelling. Psychological morbidity of lymphoedema. Cancer 72: 3248-3252. [Crossref]

8. Vodder E (1936) Le drainage lymphatique, une novelle methodetherapeutique. Paris: Sante' pour tous.

9. Földi E, Földi M, Weissleder H (1985) Conservative treatment of lymphoedema of the limbs. Angiology 36: 171-180. [Crossref]

10. Fife CE, Davey S, Maus EA, Guilliod R, Mayrovitz HN (2012) A randomized controlled trial comparing two types of pneumatic compression for breast cancerrelated lymphedema treatment in the home. Support Care Cancer 20: 3279-3286. [Crossref]

11. Charles H (1921) A System of Treatment Latham, English TC (Eds). Churchill, London, UK.

12. O’Brien BM, Sykes P, Threlfall GN, Browning FS (1977) Microlymphaticovenous anastomoses for obstructive lymphedema. Plast Reconstr Surg 60: 197-211. [Crossref]

13. Nava VM, Lawrence WT (1988) Liposuction on a lymphedematous arm. Ann Plast Surg 21: 366-368. [Crossref]

14. Brorson H (2003) Liposuction in arm lymphedema treatment. Scand J Surg 92: 287295. [Crossref]

15. Brorson H, Svensson H (1997) Complete reduction of lymphoedema of the arm by liposuction after breast cancer. Scand J Plast Reconstr Surg Hand Surg 31: 137-143. [Crossref]

16. Eryilmaz T, Kaya B, Ozmen S, Kandal S (2009) Suction-assisted lipectomy for treatment of lower-extremity lymphedema. Aesthetic Plast Surg 33: 671-673. [Crossref]

17. Brorson H (2012) From lymph to fat: liposuction as a treatment for complete reduction of lymphedema. Int J Low Extrem Wounds 11: 10-19. [Crossref]

18. Greene AK, Slavin SA, Borud L (2006) Treatment of lower extremity lymphedema with suction-assisted lipectomy. Plast Reconstr Surg 118: 118e-121e. [Crossref]

19. Schaverien MV, Munro KJ, Baker PA, Munnoch DA (2012) Liposuction for chronic lymphoedema of the upper limb: 5 years of experience. J Plast Reconstr Aesthet Surg 65: 935-942. [Crossref]

20. Damstra RJ, Voesten HG, Klinkert P, Brorson H (2009) Circumferential suctionassisted lipectomy for lymphoedema after surgery for breast cancer. Br J Surg 96: 859864. [Crossref]

21. http://www.facit.org/FACITOrg/Questionnaires

22. Sander AP, Hajer NM, Hemenway K, Miller AC (2002) Upper-extremity volume measurements in women with lymphedema: A comparison of measurments obtained via water displacement with geometrically determined volume. Phys Ther 82: 12011212. [Crossref]
23. Ryan TJ (1995) Lymphatics and adipose tissue. Clin Dermatol 13: 493-498. [Crossref]

24. Brorson H, Ohlin K, Olsson G, Karlsson MK (2009) Breast cancer-related chronic arm lymphedema is associated with excess adipose and muscle tissue. Lymphat Res Biol 7: 3-10. [Crossref]

25. Brorson H, Ohlin K, Olsson G, Nilsson M (2006) Adipose tissue dominates chronic arm lymphedema following breast cancer: an analysis using volume rendered CT images. Lymphat Res Biol 4: 199-210. [Crossref]

26. Flynn TC, Coleman WP 2nd, Field LM, Klein JA, Hanke CW (2000) History of liposuction. Dermatol Surg 26: 515-520. [Crossref]

27. Brorson H (2000) Liposuction gives complete reduction of chronic large arm lymphedema after breast cancer. Acta Oncol 39: 407-420. [Crossref]

28. Brorson H, Svensson H, Norrgren K, Thorsson O (1998) Liposuctionreduces arm lymphedema without significantly alteringthe already impaired lymph transport. Lymphology 31: 156-172. [Crossref]

29. Erickson VS, Pearson ML, Ganz PA, Adams J, Kahn KL (2001) Arm edema in breast cancer patients. J Natl Cancer Inst 93: 96-111. [Crossref]

30. Dini D, Del Mastro L, Gozza A, Lionetto R, Garrone O, et al. (1998) The role of pneumatic compression in the treatment of postmastectomy lymphedema. A randomized phase III study. Ann Oncol 9: 187-190. [Crossref]

31. Johansson K, Lie E, Ekdahl C, Lindfeldt J (1998) A randomized study comparing manual lymph drainage with sequential pneumatic compression for treatment of postoperative arm lymphedema. Lymphology 31: 56-64. [Crossref]

32. Brorson H, Svensson H (1998) Liposuction combined with controlled compression therapy reduces arm lymphedema more effectively than controlled compression therapy alone. Plast Reconstr Surg 102: 1058-1067. [Crossref]

33. Qi F, Gu J, Shi Y, Yang Y (2009) Treatment of upper limb lymphedema with combination of liposuction, myocutaneous flap transfer, and lymph-fascia grafting: a preliminary study. Microsurgery 29: 29-34. [Crossref]

34. Damstra RJ, Voesten HGJ, van Schelven WD, van der Lei B (2009) Lymphatic venous anastomosis (LVA) for treatment of secondary arm lymphedema. A prospective study of 11 LVA procedures in 10 patients with breast cancer related lymphedema and a critical review of the literature. Breast Cancer Res Treat 113: 199-206. [Crossref]

35. O’Brien BM, Mellow CG, Khazanchi RK, Dvir E, Kumar V, et al. (1990) Long-term results after microlymphaticovenous anastomoses for the treatment of obstructive lymphedema. Plast Reconstr Surg 85: 562-572. [Crossref]

36. Chang DW (2012) Lymphaticovenular bypass surgery for lymphedema management in breast cancer patients. Handchir Mikrochir Plast Chir 44: 343-347. [Crossref]

37. Brorson H, Ohlin K, Olsson G, Långström G, Wiklund I, et al. (2006) Quality of life following liposuction and conservative treatment of arm lymphedema. Lymphology 39: 8-25. [Crossref]

Copyright: (C) 2015 Doren EL. This is an open-access article distributed under the terms of the Creative Commons Attribution License, which permits unrestricted use, distribution, and reproduction in any medium, provided the original author and source are credited. 